gas. itself. The explanation of the raised levels of activity is most likely to be made in terms of the special meteorological conditions associated with fog or smoke-laden atmospheres.

We are indebted to the National Coal Board for the coal samples and to Mr. A. M. Wandless for much useful information on the samples.

W. Anderson

R. C. TURNER

Physics Department,

Institute of Cancer Research,

Royal Cancer Hospital,

London, S.W.3. March 10.

1 Anderson, W., Mayneord, W. V., and Turner, R. C., Nature, 174, 424 (1954).

\section{Occurrence of Cæsium in Fossils}

THE possibility of potassium-argon dating of fossils led to the spectrographic examination of a brachiopod (Lingula), a lamellibranch (Gryphaea) and a trilobite (Calymene) for potassium. The alkali metal spectra of Calymene showed such marked cæsium enrichment, relative to rubidium and potassium, that a rapid survey was made of the phylum Arthropoda. Two arachnids, four insects, four crustaceans and twenty-eight trilobites were analysed by a semi-quantitative method. To compare different species and genera of trilobites from a single horizon, collections were made from the Upper Silurian Wenlock Limestone at Dudley, Staffordshire. In order to check whether the sediment associated with the trilobites might have an unusual cæsium content many matrices adjacent to the fossils were analysed, collections of sediment also being made for this purpose at Dudley.

From inspection of the potassium and rubidium lines, the $\mathrm{K} / \mathrm{Rb}$ ratio is not significantly different in the trilobites and enclosing sediments and is about the same as in sediments and igneous rocks. The $\mathrm{Rb} / \mathrm{Cs}$ ratio was estimated with fair accuracy. This ratio gives a clearer indication of relative cæsium enrichment than the absolute amounts present, for which the reproducibility was poor $\left(\lambda^{\prime}=2, A\right.$ hrens $\left.{ }^{1}\right)$. The $\mathrm{Rb} / \mathrm{Cs}$ ratio is markedly lower in the trilobites (arithmetical mean $=3.9$; geometrical mean $=2 \cdot 4$ ) than in the enclosing sediment (arithmetical mean $=$

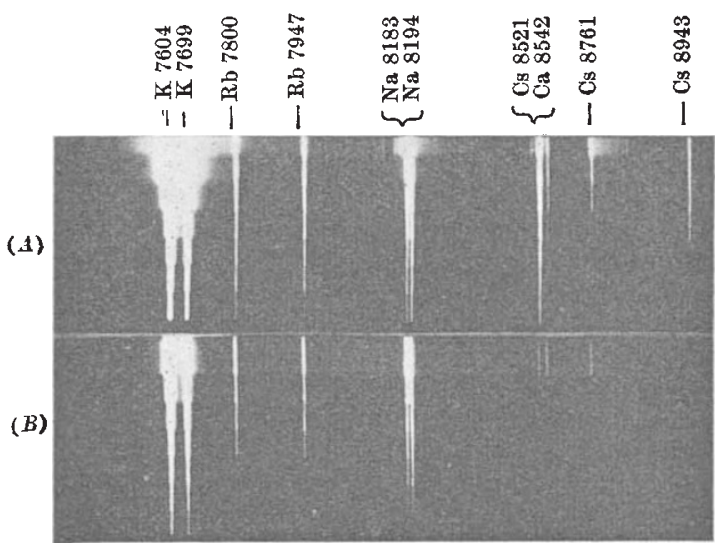
Fig.1. Alkali metal spectra of $\underset{\text { Deiphon }}{(A) \text { Deiphon; }}(B)$ matrix surrounding
19 ; geometrical mean $=15$ ). Modes determined from histograms are approximately $2 \cdot 5$ for trilobites and 15 for matrix. No significant difference was noted in the ratios of different parts of the same trilobite. Particularly low ratios were recorded for Deiphon $(\mathrm{Rb} / \mathrm{Cs} 0.36)$ and Paradoxides (Rb/Cs $=0.26)$, both spinose forms. The maximum (absolute) amount of cæsium recorded was in Deiphon, which contained $\sim 250$ p.p.m. This striking enrichment is shown in Fig. 1A. The matrix associated with Deiphon is shown in Fig. $1 B$.

Canney $^{2}$ found an $\mathrm{Rb} / \mathrm{Cs}$ ratio of 15 (arithmetical mean) for 323 sedimentary rocks. Thus the $\mathrm{Rb} / \mathrm{Cs}$ ratio of the matrix surrounding the trilobites does not differ appreciably from the average for sediments. Cæsium may have been concentrated by the trilobites during growth, or it may have become selectively absorbed after death, in which case the matrix might be expected to be distinctly impoverished in cresium. The results obtained tend to support the former view, or, if the cæsium enrichment of the trilobites was postburial, the enclosing sediment was not affected.

While it has frequently been observed that certain metallic elements, for example, copper, are enriched in organisms, it is interesting to note, in the present case, strong enrichment of one alkali element relative to the others with similar chemical properties. The cæsium enrichment is perhaps connected with its large size $\left(\mathrm{Cs}^{+}: 1.67 \mathrm{~A}\right.$.) and consequent low degree of hydration.

A spectrographic examination was also made of five genera of the phylum Brachiopoda. Of these, Lingula (the only chitinous form analysed) showed some cæsium enrichment.

\section{W. S. McKERROW}

S. R. TAYLOR

AUDRey L. Blackburn

L. H. AHRENS

Department of Geology and Mineralogy, Oxford.

May 30.

1 Ahrens, L. H., "Quantitative Spectrochemical Analysis of Silicates" (Pergamon' Press, London, 1954).

Canney, F. C., Bull. Geol. Soc. Amer., 63, 1238 (1952).

\section{Palæomagnetism of Chemical Sediments}

SINCE previous observations of remanent magnetism of sedimentary rocks have been mainly confined to detrital deposits, we would like to report on new significant results obtained with chemical deposits. In the case of detrital sediments, the question has arisen sporadically as to whether the inclination of the remanent vector is changed by the realignment of the magnetic particles upon meeting the bottom surface in the settling process and also by movements later in the compaction process. This question does not hold in the case of chemical deposits. Perhaps of more importance, these particular rocks exhibit a desirable stability of magnetization.

Some of the rocks sampled consisted of large ellipsoidal, calcareous concretions occurring in the Barnett shale of Mississippian age. These concretions appeared to be syngenetic (or nearly so). Nine locations were sampled at outcrops of the Barnett on the north-west, north, north-east and south-west sides of the Llano uplift in central Texas. The maximum distance between locations is 73 miles. 